\title{
Therapeutic Apheresis - Many Ways to Go
}

\author{
Rainer Moog \\ Institut für Transfusionsmedizin, Universitätsklinikum Essen; Germany
}

In the early days of therapeutic apheresis, the capability of processing blood with therapeutic intent gave rise to enthusiasm, sometimes spurred and sometimes tempered by the results of properly controlled clinical trials. Over time, considerable exercise has been devoted to assess the state of the art of therapeutic apheresis, and recently an evidence-based approach on the use of therapeutic apheresis in clinical practice was published [1]. This new approach was designed to provide uniformity to category assignment and disease discussion as well as comprehensive, yet condensed, information which could be shared with patients and clinical services requesting the use of therapeutic apheresis.

In this issue of Transfusion Medicine and Hemotherapy international experts in the field of therapeutic apheresis highlight how patients can be treated effectively using highly sophisticated apheresis devices. The review by Matsumoto et al. [2] summarizes the treatment of patients with inflammatory bowel disease by extracorporeal leukocyte removal therapy. The technology is distributed by Japanese corporations and is based on columns filled with polyester or cellulose acetate beads and a centrifugal cell separator. Some randomized controlled studies have been conducted showing that leukocyte removal by apheresis can be used efficiently and safely as a non-pharmacological immunomodulating therapy in inflammatory bowl disease. Filtration leukocytapheresis has been approved by Japanese health insurance policy for active colitis ulcerosa and CE marked as a medical device in Europe. Reimbursement of this modern apheresis technology by health insurances has to be negotiated in the near future depending on evidence-based studies which are currently conducted.

Promising results can be obtained by photopheresis in T-cellmediated diseases. 20 years after successful introduction of extracorporeal photochemotherapy in cutaneous T-cell lymphoma treatment of acute and chronic graft-versus-host disease refractory to conventional immunosuppressive drugs is one of its main indications [3]. The principle of photopheresis is the collection of mononuclear cells, addition of the photosensitizer 8-methoxypsoralen followed by irradiation with ultraviolet light. Finally the treated mononuclear cells are re-infused to the patient inducing changes in cellular immunity. The mechanism of immunomodulation by photopheresis is only poorly understood today and an interesting field of current research. The good response rate after extracorporeal phototherapy in the above cited diseases encouraged researchers all over the world to use photopheresis in other T-cell-mediated dysreactivities such as autoimmune diseases, dermatological diseases, and organ rejection after transplantation. Some of these studies are still ongoing, and we are expecting their results in the near future.

The work of Ullrich et al. [4] in this issue of TRANSFUSION Medicine And Hemotherapy is an example of how red blood cell exchange can be efficiently used to treat patients with alterations of erythrocytes. Hemoglobinopathies are inherited disorders of abnormal hemoglobin, and red blood cell (RBC) transfusion can be a primary or first-line adjunct therapy. Serious complications of sickle cell anemia include acute chest syndrome, stroke, priapism, and splenic, hepatic and renal dysfunction. In acute life- or organ-threatening complications, erythrocytapheresis can be carried out to replace altered $\mathrm{RBC}$ with normal $\mathrm{RBC}$ without increasing blood viscosity and volume overload. Long-term erythocytapheresis has the distinctive advantage of markedly reducing transfusion-associated iron overload which is well documented by liver biosusceptometry in the present review [4]. Rare indications for $\mathrm{RBC}$ exchange are babesiosis, severe malaria and erythropoietic protoporphyria but the strength of evidence of therapeutic apheresis for these diseases has to be proven. We are looking forward to future randomized trials in this interesting field of therapeutic apheresis.

\begin{tabular}{ll}
\hline KARGER & @ 2008 S. Karger GmbH, Freiburg \\
$\begin{array}{l}\text { Fax +4976145207 14 } \\
\begin{array}{l}\text { E-mail Information@Karger.de } \\
\text { www.karger.com }\end{array}\end{array}$ & $\begin{array}{l}\text { Accessible online at: } \\
\text { www.karger.com/tmh }\end{array}$
\end{tabular}

Prof. Dr. Rainer Moog

Institut für Transfusionsmedizin, Universitätsklinikum Essen

Hufelandstraße 55, 45122 Essen, Germany

Tel. +49 201 723-1550, Fax -5945

E-mail rainer.moog@uni-due.de 


\section{References}

1 Szczepiorkowski ZM, Bandarenko N, Kim HC, Linenberger ML, Marques MB, Sarode R, Schwartz J, Shaz BH, Weinstein R, Wirk A, Winters JL: Guidelines on the use of therapeutic apheresis in clinical practice-evidence-based approach from the apheresis applications committee of the American Society for Apheresis. J Clin Apheresis 2007;106: 106-175.
2 Matsumoto T, Fukunaga K, Kamikozuru K, Tozawa K, Yokojama Y, Kusaka T, Onishi K, Miwa H, Nakamura S: Cytapheresis as a non-pharmacological therapy for inflammatory bowel disease. Transfus Med Hemother 2008;35(1):DOI 10.1159/ 000111763.
3 Perseghin P: Extracorporeal photochemotherapy (ECP) as a challenging treatment for cutaneous Tcell lymphoma, acute and chronic graft-versus-host disease, organ rejection and T-lymphocyte-mediated autoimmune diseases. Transfus Med Hemother 2008;35(1):DOI 10.1159/000111755.

4 Ullrich H, Fischer R, Grosse R, Kordes U, Schubert C, Altstadt B, Andreu G: Erythrocytapheresis: do not forget a useful therapy! Transfus Med Hemother 2008;35(1):DOI 10.1159/000112044. 